\title{
Three-Dimensional Soil Resistivity Inversion Using Patching Method
}

\author{
Qi You ZHOU*, Jun SHIMADA** and Akira SATO***
}

\begin{abstract}
To apply Electrical Resistivity Tomography (ERT) in monitoring temporal and spatial variation of soil water, by using finite-element method as forward modeling, we proposed a patching algorithm of inversely calculating 3D soil resistivity in this paper. From finite-element forward modeling, sensitivity calculation to formation of initial model parameters, we systematically described the inversion calculation process of using patching algorithm. At the end, we gave out results about two numerical experiments and one field measured data inversion to illustrate the effectiveness of the algorithm. By patching algorithm, the initial soil resistivity model is step by step modified to make the calculated potential approximate that measured. Each measurement event (group of pole-pole array measurements which have same current electrode and input current) composes a step of modification to the model. This algorithm is appropriate when the data number for one measurement event is quite less than the parameter number of the model and the measurement event number varies with the equipment capacity or prospecting objectives, and even when the resistivity changes with time. Numerical experiments and field measured data inversion indicated the effectiveness of the inverse algorithm, but also revealed the difficulty of completely inversely calculating out the $3 \mathrm{D}$ subsurface soil resistivity only by using the data measured at the soil surface.
\end{abstract}

Key words : finite-element method, inverse calculation, soil resistivity, patching method

\section{Introduction}

Successful application of dc Electrical Resistivity Tomography (ERT) in monitoring temporal and spatial variation of soil water depends on the establishment of relationship between soil water content and soil resistivity, and the reasonable estimation of soil resistivity from the measured data. While the relationship between soil water content and soil resistivity can be constructed by experiments, the reasonable estimation of soil resistivity can only be reached by finding an efficient algorithm of inverse calculation. Quite different from the interpretation of geological structures, where the resistivity changes little with time, the estimation of soil resistivity has to be made in the context of timechanging resistivity. The very small scale heterogeneity of soil resistivity spatial distribution also limits the traditional application of simplifying

\footnotetext{
* Doctoral Program in Geoscience, University of Tsukuba (e-mail: qyzhou@atm.geo.tsukuba.ac.jp)

** Institute of Geoscience, University of Tsukuba（会員）

*** Engineering Development Section, Kowa Company
}

three-dimensional (3D) resistivity anomalies to a two-dimensional (2D) resistivity anomalies. Thus a practical 3D inverse algorithm is vitally needed.

There are a number of reported studies about $2 \mathrm{D}$ and $3 \mathrm{D}$ inverse interpretation of geological structures, however none of them related with the 3D interpretation of soil resistivity. For the 3D interpretation of geological structure, DEY and MORRISON $^{4)}$ developed a 3D forward modeling routine by using finite-difference method. Following this forward modeling method, PARK and $\mathrm{VAN}^{8)}$ developed a $3 \mathrm{D}$ inversion procedure by using maximum likelihood inverse theory. Considering the suitability of finite-element method (FEM) in modeling complex geometry, COGGON $^{3)}$ derived an energy functional for $2 \mathrm{D}$ electromagnetic problems and proposed finiteelement method of electromagnetic and electrical modeling. PRIDMORE et al. ${ }^{11}$ extended this method to 3D problem by using tetrahedral elements and compared their solution to the integral equation method. HOLCOMBE and JIRACEK ${ }^{6)}$ developed a method of accommodating 3D topographic variations by using distorted hexahedral 
elements. By using conjugate gradient relaxation technique, ZHANG et al. ${ }^{17)}$ developed a 3D dc resistivity forward modeling and inversion algorithm, and proposed a method of bypassing the actual computation of the sensitivity matrix. Besides finite-difference method, finite-element method and transmission-network analogy method, there are also integral equation method $^{7,10)}$ and alpha centers method ${ }^{9,12)}$ which deal with the forward and inverse calculation of dc resistivity modeling. These techniques provided valuable information for the interpretation of geological structures, however, it is difficult to use these techniques directly to the soil resistivity anomaly interpretation, because different from geological bodies, soil resistivity distribution has smaller scale (decimeters), more complex spatial structure and time-changing features.

In this paper, by using finite-element method for the 3D forward modeling problem, we proposed a practical simple method of inversely calculating the $3 \mathrm{D}$ soil resistivity. This inverse calculation algorithm considered the features of soil resistivity, was proved to be efficient and appropriate for the application of Electrical Resistivity Tomography in soil water monitoring.

\section{Forward problem}

\subsection{Finite-element forward modeling}

The Poisson's equation of controlling steadystate electrical potential distribution in the space is

$$
\nabla \cdot \sigma \nabla \phi=\nabla \cdot J_{s}
$$

where $\phi$ is electrical potential, $\sigma$ is conductivity of the earth, electrical resistivity $\rho=1 / \sigma, J_{s}$ is diverging current density. For a point electrode located at position $\left(x_{0}, y_{0}, z_{0}\right), \nabla \cdot J_{s}$ becomes $I \delta(x$ $\left.-x_{0}\right)\left(y-y_{0}\right)\left(z-z_{0}\right)$, where $I$ is current, $\delta(x)$ is Dirac delta function. According to minimum theorem, solving equation (1) equals to minimizing the following functional ${ }^{11}$ :

$$
F(\phi)=\sum_{j} \int_{V_{j}}\left[\sigma_{j}(\nabla \phi)^{2}-2 \phi \nabla \cdot J_{s}\right] d V_{j}
$$

where the spatial region is divided into elements over which $\sigma$ is a constant. Assuming the global trial solution of equation (1) is $\phi=\sum_{j=1}^{n} N_{j} \phi_{j}$, where $\phi_{j}$ is the potential at node $j$, then $\stackrel{j=1}{\text { minimiz- }}$ ing functional $F(\phi)$ results in linear equation :

$$
G \phi=f
$$

where $G$ is a sparse, symmetric, banded and positive-definite coefficient matrix, $\phi$ is the unknown electrical potential vector, $f$ is a vector of describing the known sources of current. By solving equation (3) together with boundary condi-

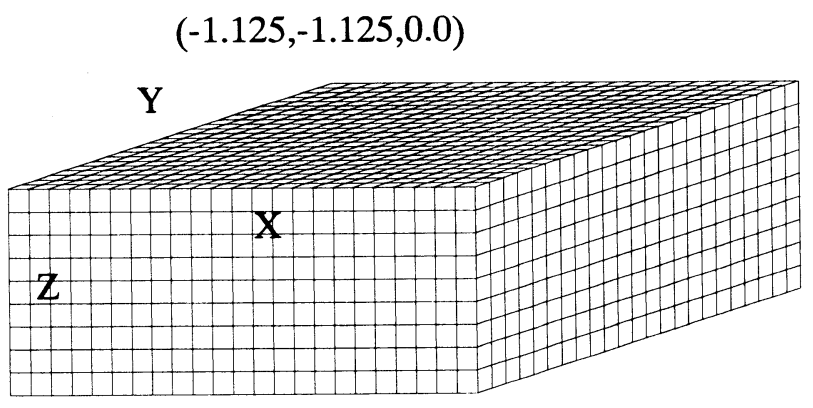

$(4.625,4.625,2.25)$

\section{Element size: $\quad 0.25 \mathrm{~m} \times 0.25 \mathrm{~m} \times 0.25 \mathrm{~m}$ \\ Total nodes: $24 \times 24 \times 10$ \\ Region size: $\quad 5.75 \mathrm{~m} \times 5.75 \mathrm{~m} \times 2.25 \mathrm{~m}$}

Figure 1 Element division for 3D FEM electrical potential calculation

三次元有限要素法電位計算の要素分割

tions, then electrical potential at each node can be obtained.

Figure 1 shows the subdivision scheme of our finite-element forward modeling. As indicated in the figure, we used the same size hexahedron as the elements. Although this makes a little more memory needed, it makes the automatic construction of equation (3) become possible, and the program code adjustable for different element subdivision scheme. Solution of equation (3) with boundary conditions was obtained by conjugate

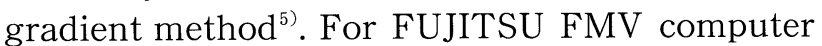
with $150 \mathrm{MHz} \mathrm{CPU}$ and 128 Megabyte RAM, forward calculation with $24 \times 24 \times 10$ nodes needs less than half a minute.

\subsection{Boundary conditions}

For the earth-air interface, the homogeneous Neumann boundary condition $(\partial \phi / \partial z=0)$ was used. In fact, this Neumann condition had been included in equation (2). For the boundary conditions on the sides and bottom, ZHANG et al. ${ }^{17)}$ analyzed the problems resulted from Dirichlet type boundary condition and that resulted from using analytical solution of homogeneous medium as the boundary conditions. DEY and MORRISON ${ }^{4)}$ proposed a mixed boundary condition which relates the potential at the boundary nodes with the angle $\theta$ between the radial distance $r$ from the geometrical surface center and the outward normal spatial coordinate on the boundaries. However, for heterogeneous medium, the potential at the boundary nodes not only changes with the angle $\theta$ and distance $r$, but also changes with the resistivity of neighboring elements. Because usually, at the neighbor of high resistivity anomaly, there is a relative high 
potential, at the neighbor of low resistivity anomaly, there is a relative low potential ${ }^{2)}$, here we use the analytical solution of homogeneous medium as the potential at the boundary nodes, but the resistivity of homogeneous medium is calculated by averaging the resistivity at neighboring elements.

\subsection{Sensitivity calculation}

For $\Delta \rho_{i}$ change of resistivity at element $i$, there is a $\Delta \phi_{j}$ change of potential at point $j$, then sensitivity $S_{i j}$ (partial derivatives) is defined as $\Delta \phi_{j} /$ $\Delta \rho_{i}$. If we only consider the sensitivity at receivers, and there are $n$ current sources, $m$ receivers, $s$ elements, then matrix $S$ has $n \times m \times s$ elements. This means that $n \times m \times s$ forward calculations are needed. When the maximum likelihood inverse theory developed by TARANTOLA and VALETTE $^{16)}$ is used to the $3 \mathrm{D}$ resistivity inversion of heterogeneous medium, each iteration needs a update of sensitivity matrix $S$. The great amount of calculations makes the 3D inversion almost impossible.

The sensitivity calculation method which we used at here follows the idea of BOERNER and HOLLADAY ${ }^{1}$. That is, the sensitivity for heterogeneous medium can be approximated by that of homogeneous half-space medium. By using 300 $\Omega \mathrm{m}$ (the average of measured soil apparent resistivity) as the resistivity of homogeneous half-space medium, and considering the symmetry of potential distribution for point current source, we calculated the pole-pole array sensitivity for a point current source located at the central surface of the region. Sensitivity for other point current sources were obtained by projecting or shifting the central point current source to the current source position.

Figure 2 shows the 3D distribution of sensitivity for a pole-pole array over a $300 \Omega \mathrm{m}$ homogeneous half-space. This figure was obtained by forward calculation with current electrode located at $(1.5 \mathrm{~m}, 1.5 \mathrm{~m}, 0.0 \mathrm{~m})$, potential electrode located at $(2.0 \mathrm{~m}, 1.5 \mathrm{~m}, 0.0 \mathrm{~m})$, and current equal to $10 \mathrm{~mA}$. From Figure 2, we can see that both at the area around the electrodes and at the area between the two electrodes, the sensitivity has a very high absolute value. This indicated that the potential measured on the potential electrode will be very sensitive to the resistivity changes at this two areas. However because the sensitivity has different sign at the two areas, the resistivity change will have opposite effects on the measured potential. At other area, generally there is a very low and positive sensitivity.
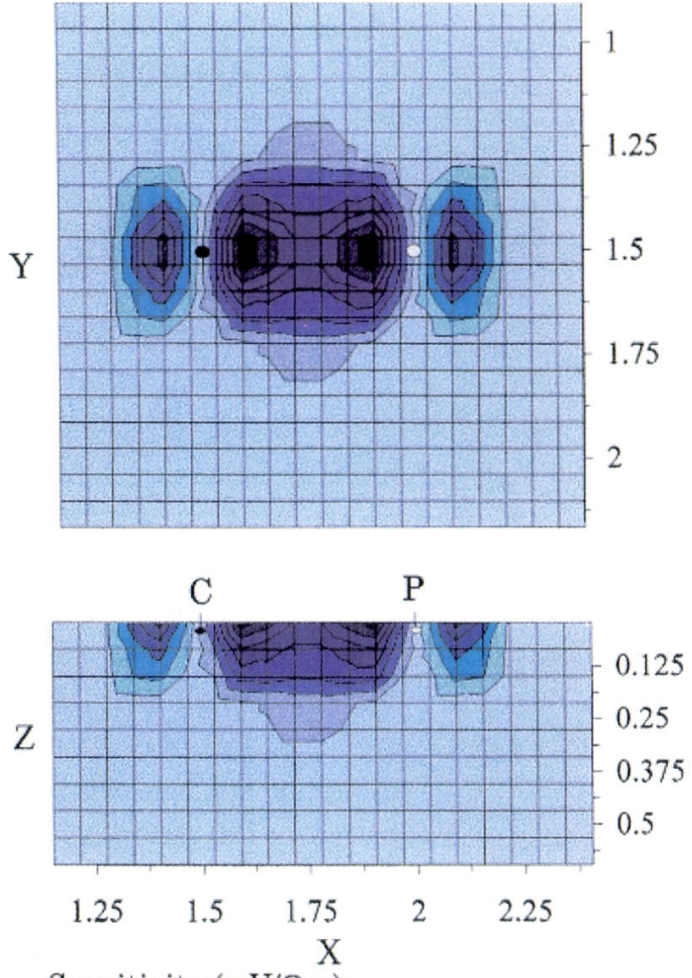

Sensitivity $(\mathrm{mV} / \Omega \mathrm{m})$ :

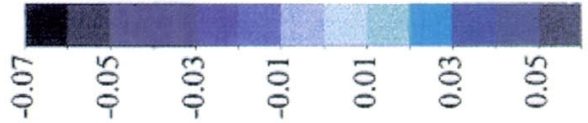

Figure 2 3D sensitivity distribution for a pole-pole array over $300 \Omega \mathrm{m}$ homogeneous half-space $300 \Omega \mathrm{m}$ の均質半空間上での二極法による三次元感度 分布

\section{Inverse algorithm}

\subsection{Patching method of resistivity perturba- tion}

Inverse problem always is the focus of scientific investigation. Difficulty of inversion lies in that most of the inverse problems are nonunique. One method of obtaining a solution to these nonunique inverse problems is maximum likelihood inverse theory which provides the best fit to the data relative to the a priori information. By this method, according to TARANTOLA and VALETTE $^{16)}$ and TARANTOLA ${ }^{15)}$, the perturbation vector for model parameters can be obtained by

$$
\begin{aligned}
& \left(S_{k}^{T} R_{d d}^{-1} S_{k}+R_{m m}^{-1}\right) \Delta \rho_{k} \\
& =S_{k}^{T} R_{d d}^{-1}\left(d-G\left(\rho_{k}\right)\right)+R_{m m}^{-1}\left(\rho_{0}-\rho_{k}\right)
\end{aligned}
$$

where $S$ is sensitivity matrix, $d$ is observed data vector, $\rho$ is the model parameter(resistivity) vector, $G$ is the forward modeling operator, and $R_{d d}$, $R_{m m}$ is covariance matrix for data and model parameter, $\rho_{0}$ is a priori parameter vector, $\Delta \rho_{k}$ is the $k$ th perturbation vector for the inverse iteration. In the ERT measurements for soil water monitoring, the electrical potential measurement is 
usually sequentially made for a number of current sources, and for one current source, the measured potential data number is often less than the model parameter number. At the same time, during the measuring period, because of the soil water transport, the soil resistivity may change with time. All of these characteristics make the direct application of equation (4) in the inversion calculation of soil resistivity become difficult. Therefore, by adapting equation (4) to the characteristics of ERT measurement for soil water monitoring, we proposed a practical simple method of calculating the perturbation vector for soil resistivity inversion.

For the pole-pole array measurements, all of the measurements with same current electrode and same input current are defined as one measurement event. For each event, only once calculation of forward problem is needed to get the potential. If there are $m_{i}$ measurements or receivers for event $i$, then $m_{i}$ potential differences between modeled and measured can be obtained and sensitivity matrix $S^{i}$ of event $i$ only has $m_{i} \times s$ elements. According to equation (4), the perturbation $\Delta \rho$ is linearly related with potential difference $\Delta d(d-G$ $\left.\left(o_{k}\right)\right)$. On the other hand, perturbation $\Delta \rho_{j}$ at element $j$ also relates with the sensitivity of different receivers at this element, the larger the sensitivity, the greater the perturbation resulted from this receiver should be. Thus the perturbation $\Delta \rho_{k j}^{i}$ at element $j$ resulted from the $k$ th receiver of event $i$ can be expressed as :

$$
\Delta \rho_{k j}^{i}=S_{k j}^{i} \Delta d_{k}^{i}\left(k=1,2, \cdots, m_{i} ; j=1,2, \cdots, s\right)
$$

where $s$ is the total element number. The total perturbation $\Delta \rho_{j}^{i}$ at element $j$ should be the sum of perturbations from different receivers :

$$
\Delta \rho_{j}^{i}=\sum_{k=1}^{m_{i}} \Delta \rho_{k j}^{i}=\sum_{k=1}^{m_{i}} S_{k j}^{i} \Delta d_{k}^{i}(j=1,2, \cdots, s)
$$

Thus perturbation vector $\Delta \rho^{i}$ resulted from event $i$ is obtained. After smooth processing, the perturbation vector $\Delta \rho^{i}$ is added to the initial model parameters to update the model parameters. Then the perturbation of model parameters is repeated for the next event. In this way, the model parameters are sequentially updated by using the measured data from each event. One cycle of events composes one inversion iteration. This procedure is repeated until a misfit between the total measured and modeled data is reduced to an acceptable root-mean-square (RMS) level.

Because the sensitivity matrix for heterogeneous medium is approximated by that of homogeneous medium, sometimes the perturbation calculated from equation (6) will result in the divergence of $\Delta d$. This means that the resistivity at the areas where the sensitivity absolute value is low has become the main factors of controlling potential distribution. At this time, we calculate the perturbation by using the minus sensitivity as positive sensitivity. If we find that this sign inversion of minus sensitivity can not make the $\Delta d$ vector converge further, then we use the original sensitivity again. This method works efficiently, especially when the initial model parameters are not properly given.

The proposed method of calculating perturbation vector considered each measurement event respectively, thus accommodated the resistivity change between measurement events. For every measurement event independently contributes to the model parameter improvements, it is appropriate for measurement instrument with different channel number and for different objective of measurement. Because the perturbation vector given by equation (6) has the characteristics of being large at the neighbor of electrodes, gradually decreasing to zero with the distance from the electrodes, perturbation resulted from each event like a patching process, we call this perturbing method as patching method.

\subsection{Initial model parameters}

Few of the resistivity inversion studies reported the method of finding a 3D initial (starting) model parameters. ZHANG et al. ${ }^{17)}$ used the average value determined by the nearest sourcereceiver combination as the starting resistivity of shallow layers. For dynamically monitoring the variation of soil water by soil resistivity inversion method, an algorithm which can give proper initial model resistivity is very important. Considering that the apparent resistivity has reflected the general characteristics of the soil resistivity, in this study, by following steps, we use the apparent resistivity from pole-pole array and Wenner array to compose the initial soil resistivity model of inverse calculation. (1) Apparent resistivity from pole-pole array measurements are calculated and indicated at the middle point of the two electrodes with depth equal to the electrode interval ${ }^{13)}$. Apparent resistivity from Wenner array measurements are also calculated but indicated at the middle point of the four electrodes with depth equal to the interval of potential electrodes. (2) Based on these basic apparent resistivity data, soil resistivity for every element is obtained by three-dimensional distance weight interpolation method. (3) The initial 
soil resistivity model is then three-dimensionally processed to smooth the abrupt change of soil resistivity at neighboring elements. (4) Finally, the initial soil resistivity model is multiplied by an empirical constant vector. This empirical constant vector is determined by referencing the soil water content profile, geological information about the soil stratum, and known information about soil resistivity. For one measurement site, only one empirical constant vector is needed.

\section{Results and discussions}

\subsection{Numerical experiments}

To assess the effectiveness of the proposed inverse algorithm, two model numerical experiments were conducted. Sixty-four electrodes were "buried" on the $3.5 \mathrm{~m} \times 3.5 \mathrm{~m}$ surface by $8 \times 8$ grid, with grid gap equal to $0.5 \mathrm{~m}$. Along $\mathrm{X}, \mathrm{Y}, \mathrm{XY}$ and -XY directions, total 572 pole-pole array "measurements" were conducted and were used to form the initial resistivity model of inverse calculation (Figure 3). The total element number for forward calculation is $23 \times 23 \times 9$ with element size equal to $0.25 \mathrm{~m} \times 0.25 \mathrm{~m} \times 0.25 \mathrm{~m}$ (Figure 1). Inverse calculated results only at the central part of the upper six layers were used for the analysis.

For each layer, model 1 \# has a low resistivity body at the central part, high resistivity bodies at the four corners, with the resistivity at other parts ranges in the between. Considering that the

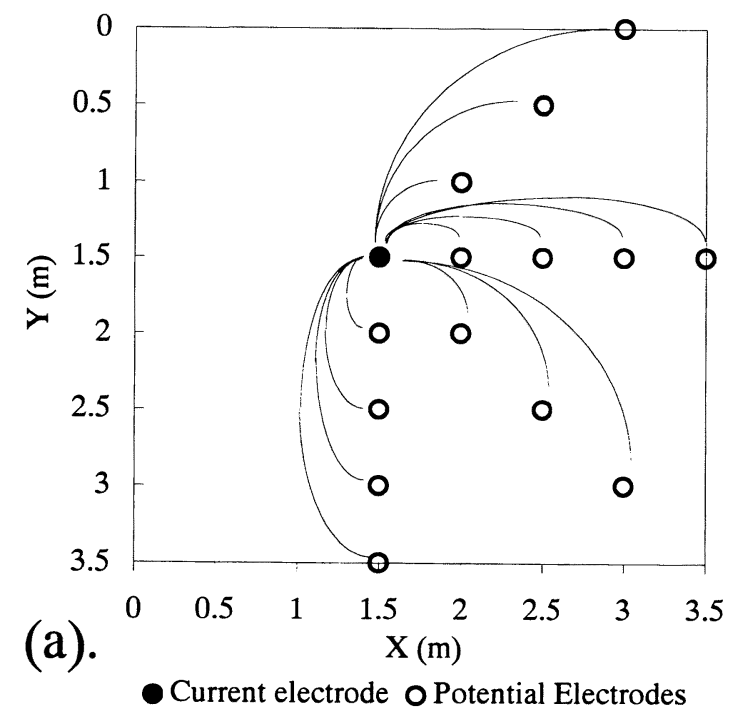

soil water content generally increases with depth, the resistivity of model $1 \#$ is given to decrease with the depth (layer). Figure 4 shows the 3D resistivity distribution inversely calculated by six (the number where RMS value has approximately stabilized) iterations together with that of model 1 \#. From this figure, it can be seen that although the abrupt boundary of resistivity changing in the model is not clearly indicated in the inverse results and the inversely calculated resistivity is not exactly same as that of the model, the resistivity distribution pattern is really reproduced, especially for the upper four layers. Figure 5 shows the linear relationship between inversely calculated resistivity and model resistivity. For $87.33 \%$ of the total data, relative errors ranged between $-20 \%$ and $20 \%$.

For model 2\#, except $50 \Omega \mathrm{m}$ low resistivity body at the central part of the third and fourth layer, all of the resistivity at other parts are given $200 \Omega \mathrm{m}$. Figure 6 shows the 3D model resistivity distribution and the inversely calculated resistivity after six (same as model 1 \#) iterations. From this figure, it is clear that the original resistivity distribution pattern at the third and fourth layer was also reproduced by the inverse algorithm. However, there appeared artificial abnormal bodies at the first two layers. This indicated that when only using the 572 pole-pole array data measured at the surface, it is difficult

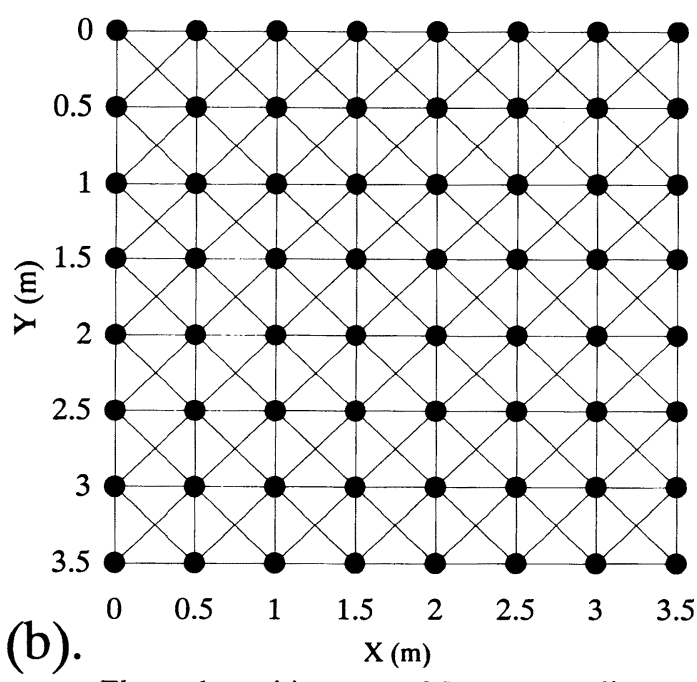

- Electrode position

Figure 3 Resistivity measurement pattern for 3D Electrical Resistivity Tomography by pole-pole array and Wenner array. (a). An example of measurement events where each arc line indicates a electrode combination of pole-pole array; (b). Measurement pattern which consists of all of the measurement events. Measurements for Wenner array are also conducted at this four directions.

二極法とウェンナ法による三次元比抵抗卜モグラフィの比抵抗測定パターン. (a).測定イベントの一例で, 弧 線は二極法電極の配置を意味する; (b).すべての測定イベントから形成された測定パターン。四極法の測定も この四つの方向で行う. 

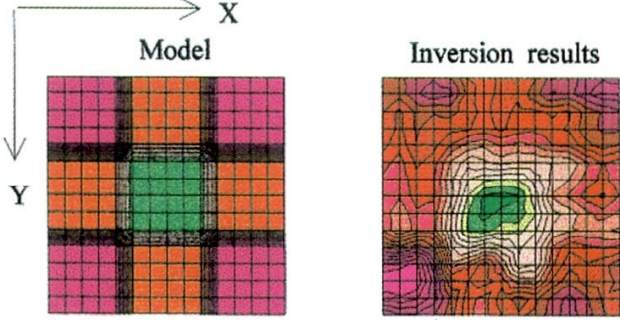

Layer $1(\mathrm{Z}=0.00-0.25 \mathrm{~m})$
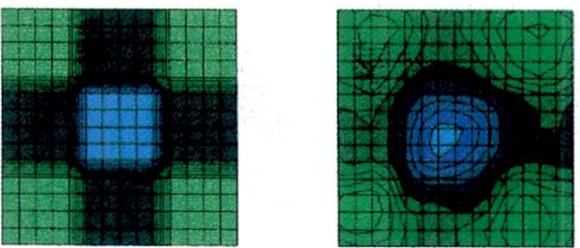

Layer $2(\mathrm{Z}=0.25-0.50 \mathrm{~m})$

Layer $3(\mathrm{Z}=0.50-0.75 \mathrm{~m})$
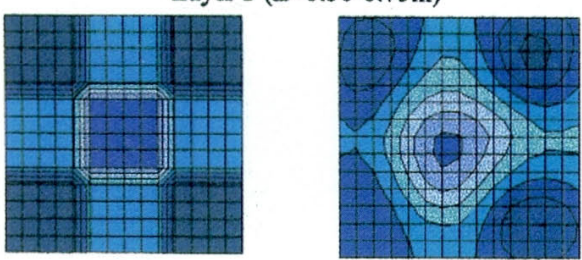

Resistivity $(\Omega \mathrm{m})$ :

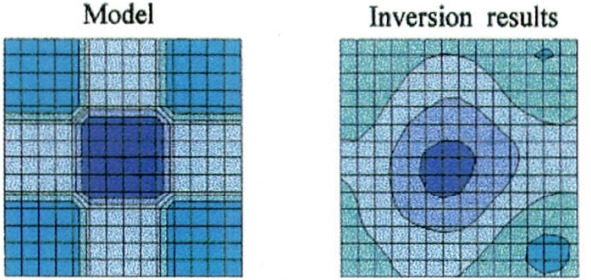

Layer $4(\mathrm{Z}=0.75-1.00 \mathrm{~m})$
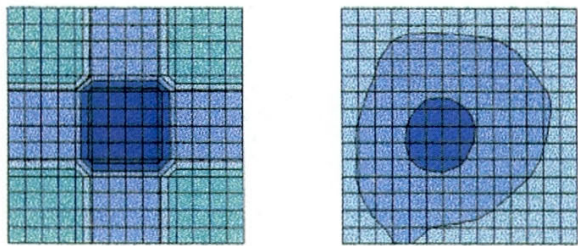

Layer $5(\mathrm{Z}=1.00-1.25 \mathrm{~m})$

Layer $6(\mathrm{Z}=1.25-1.50 \mathrm{~m})$
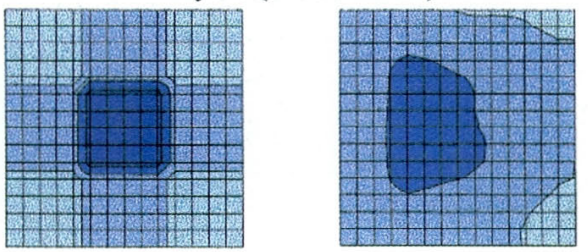

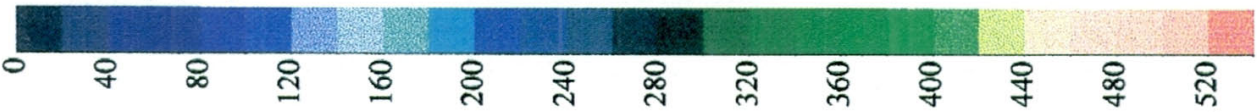

Figure 4 Comparison between inversely calculated resistivity and that of model 1 \# インバージョン計算による比抵抗と 1 \# モデル比抵抗との比較

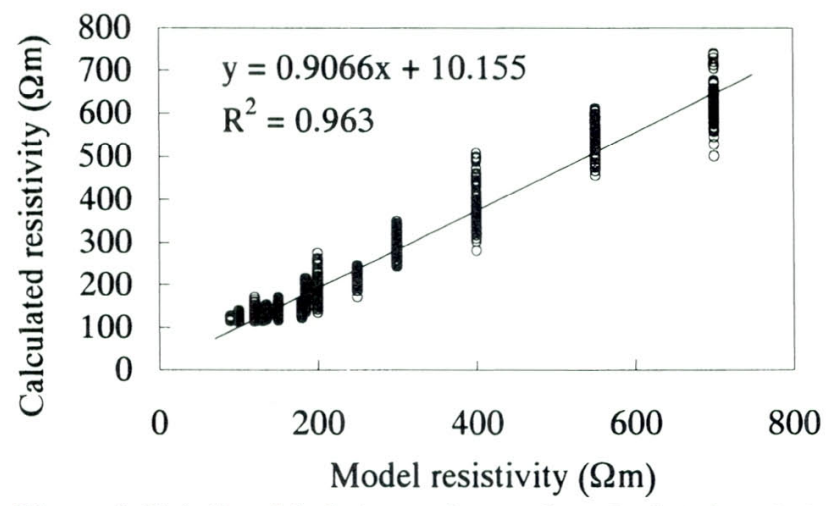

Figure 5 Relationship between inversely calculated resistivity and that of model 1 \#

インバージョン計算による比抵抗と $1 \#$ モデル比抵抗と の関係

for the inverse algorithm to distinguish the vertical changes of anomaly.

\subsection{Field experiments}

To further investigate the ability of the algorithm in inversely calculating soil resistivity, field data inversion was made. The field experiments were conducted at the experimental field of Environmental Research Center, University of Tsukuba (Ibaraki, Japan) by using a 216 channel dense electrode electrical prospecting equipment (Next-
64 made by Kowa Co., Japan). Experiment area and electrode arrangement are the same as that in numerical experiments. But, in addition to the 572 pole-pole measurements in the numerical experiments at X, Y, XY and - XY directions, 170 Wenner array measurements were also conducted at the four directions (Figure 3) and were used to compose the initial soil resistivity model together with the pole-pole array data.

Inverse calculations for measurement at 12:0012:40 Jul. 22,1996 were conducted. Figure 7 shows the inversely calculated soil resistivity planar distribution at the upper six layers. The fact that there is a high resistivity area (northeast) at the right part of the image, a low resistivity area (southwest) at the left part of the image, and these two resistivity abnormal areas gradually disappear with depth is clearly understood. For soil with homogeneous matrix, high resistivity means relative low soil water content, the low resistivity means relative high soil water content. If we assume that the soil matrix at the experiment site is homogeneous, thus the inversely calculated soil resistivity spatial distribution pattern 

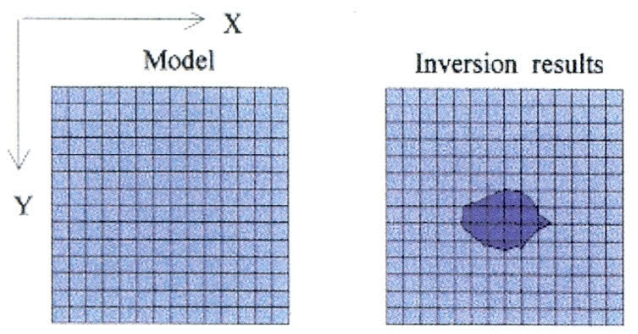

Layer $1(\mathrm{Z}=0.00-0.25 \mathrm{~m})$
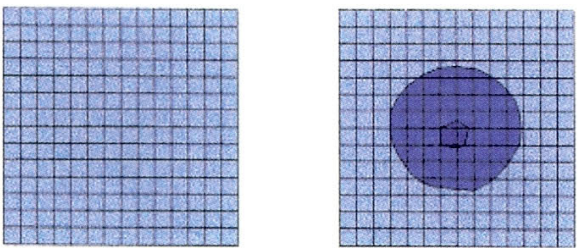

Layer $2(Z=0.25-0.50 \mathrm{~m})$

Layer $3(\mathrm{Z}=0.50-0.75 \mathrm{~m})$
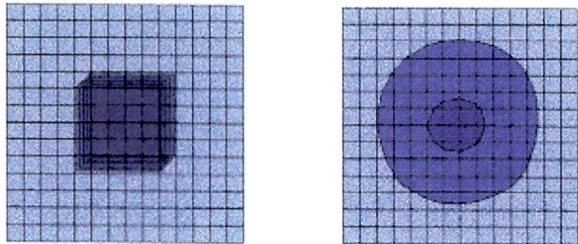

Model

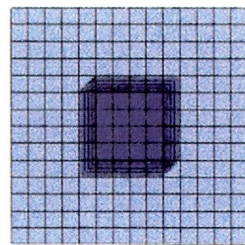

Layer $4(Z=0.75-1.00 \mathrm{~m})$
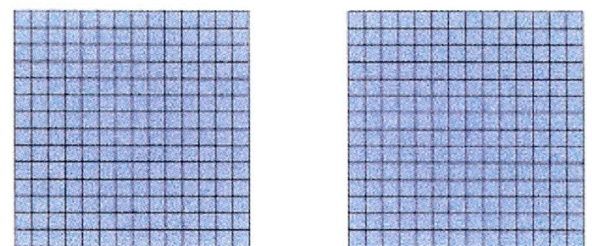

Layer $5(Z=1.00-1.25 \mathrm{~m})$

Layer $6(\mathrm{Z}=1.25-1.50 \mathrm{~m})$
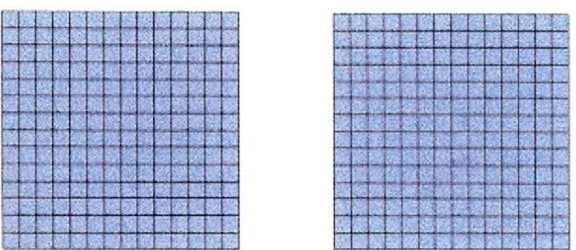

Resistivity $(\Omega \mathrm{m})$ :

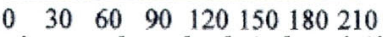

Figure 6 Comparison between inversely calculated resistivity and that of model 2 \# インバージョン計算による比抵抗と 2 \# モデル比抵抗との比較

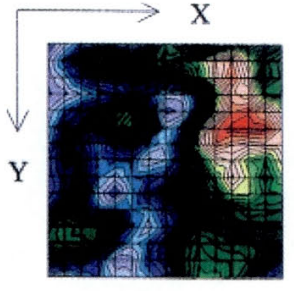

Layer $1(\mathrm{Z}=0.00-0.25 \mathrm{~m})$

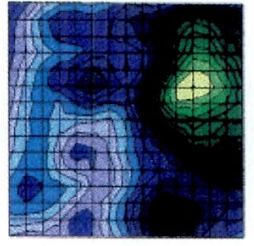

Layer $2(\mathrm{Z}=0.25-0.50 \mathrm{~m})$ Layer $3(Z=0.50-0.75 \mathrm{~m})$

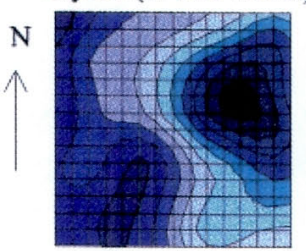

Resistivity $(\Omega m)$

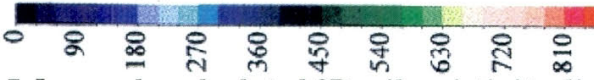

Figure 7 Inversely calculated 3D soil resistivity distribution at 12:00-12:40 Jul. 22,1996

インバージョン計算による1996年7月22日12時00分から 12 洔40分までの三次元上㙵比抵抗分布 reflects the soil water content spatial distribution pattern. This pattern is just rightly consistent with the vegetation distribution pattern of the experiment site where there are dense and high grasses at the left side, and sparse and low grasses at the right side. In addition, according to SHIMADA et $a .^{14)}$, at the right side of the experiment site, the soil had been once dug out to install the Heat-Probe Type soil moisture sensors in 1990. The position with high resistivity at the right side rightly is the position of the backfill.

To further support the rightness of the inversely calculated soil resistivity distribution, we analyzed the variation of potential errors. Figure 8 shows the decreasing of potential RMS misfit value with iteration number. It is clear from this figure that the RMS misfit value decreases very rapidly at the initial several iterations, then with the number of iteration, the RMS misfit value gradually gets stabilized. This rapid decreasing of RMS value at the initial several iterations clearly indicated the efficiency of the proposed inversion algorithm. The stabilization of RMS value at the iterations afterwards showed that there are some errors resulted from other factors such as measurement error, electrode displacement and time delay of measurement in the potential errors. 


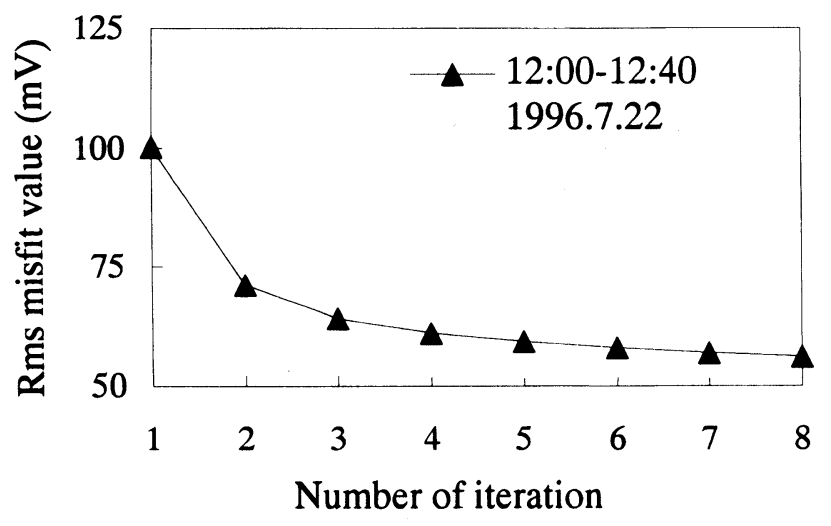

Figure 8 Decreasing of potential RMS misfit value with iteration number

反復計算回数による電位RMS残差値の衰減

Potential errors resulted from these factors can not be eliminated just by the inverse calculation. That is, with stabilization of RMS value the inversion gradually reaches its best limits.

Figure 9 shows the spectral distribution of potential errors after eight iterations and the simulated results (dash line) about the spectral distribution by summing three normal distribution functions. If we assume that the error distribution from other factors all are normal distribution, then the clear good fitness between data and the simulation further supports the conclusion that in the potential errors there are errors from other factors. The symmetric shape and the small central value $(-15.176 \mathrm{mV})$ of the spectral distribution then indicated that the inverse calculated soil resistivity has approximated the field soil resistivity very much.

\section{Concluding remarks}

We proposed a patching algorithm of inversely calculating 3D soil resistivity by using finiteelement method as the forward modeling. By this inversion algorithm, the initial soil resistivity model is step by step modified to make the calculated potential approximate that measured. Each measurement event composes a step of modification to the model. Because each measurement event contributes to the improvement of resistivity model independently, the algorithm is appropriate when the data number for one measurement event is quite less than the parameter number of the model and the measurement event number varies with the equipment capacity or prospecting objectives, and even when the resistivity changes with time. This makes the application of dc Electrical Resistivity Tomography in monitoring the temporal and spatial variation

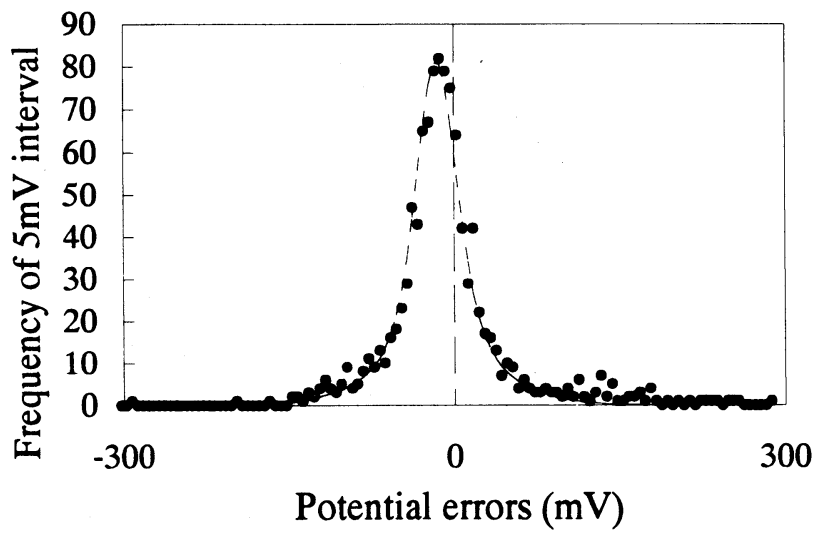

- Frequency data - - - - Simulated results

Figure 9 Spectral distribution of potential errors after eight iterations

反復計算八回目後の電位誤差のスペクトル分布

of soil water become possible. Numerical experiments and field measured data inversion indicated the effectiveness of the inverse algorithm, but also revealed the difficulty of completely inversely calculating out the $3 \mathrm{D}$ subsurface soil resistivity only by using the data measured at the soil surface. By adding more measurement events at deep soil to the inverse calculation, we believe that the inversely calculated 3D subsurface soil resistivity will further approximate the real soil resistivity in the future.

\section{Acknowledgments}

This work is a part of research project about soil water monitoring by using Electrical Resistivity Tomography which is partially supported by Special Research Project of Global Environmental Change, University of Tsukuba, Nissan Science Foundation, and Scientific Research Fund by Ministry of Education, Science, Sports, and Culture, Japan (08408003). The authors are grateful to Professor Tadashi TANAKA at University of Tsukuba and Mr. Koichi SUZUKI at Central Research Institute of Electric Power Industry for their guidance and useful suggestions.

\section{References}

1) BOERNER, D. E. and HOLLADAY, J. S. (1990): Approximate Frechet derivatives in inductive electromagnetic soundings, Geophysics, 55(12), 1589-1595.

2) CHANG CHUN GEOLOGICAL INSTITUTE (1980): Physical prospecting course for hydrogeoloy and engineering geology, Geology Publisher of China, 408p*.

3) COGGON, J. H. (1971): Electromagnetic and electrical modeling by the finite element method, Geophysics, 36(1), 
132-155.

4) DEY, A. and MORRISON, H. F. (1979): Resistivity modeling for arbitrarily shaped three-dimensional structures, Geophysics, 44(4), 753-780.

5) HAGEMAN, L. A., and YOUNG, D. M. (1981): Applied iterative methods, Academic Press, New York, 386p.

6) HOLCOMBE, H. T. and JIRACEK, G. R. (1984): Threedimensional terrain corrections in resistivity surveys, Geophysics, 49(4), 439-452.

7) HOHMANN, G. W. (1975): Three-dimensional induced polarization and electromagnetic modeling, Geophysics, 40(1), 309-324.

8) PARK, S. K. and VAN, G. P. (1991): Inversion of pole-pole data for 3D resistivity structure beneath arrays of electrodes, Geophysics, 56(7), 951-960.

9) PETRICK, W. R. Jr., SILL, W. R., and WARD, S. H. (1981): Three-dimensional resistivity inversion using alpha centers, Geophysics, 46(8), 1148-1162.

10) POIRMEUR, C. and VASSEUR, G. (1988): Three-dimensional modeling of a hole-to-hole electrical method: Application to the interpretation of a field survey, Geophysics, 53(2), 402-414.

11) PRIDMORE, D. F., HOHMANN, G. W., WARD, S. H. and SILL, W. R. (1981): An investigation of finite-element modeling for electrical and electromagnetic data in three dimensions, Geophysics, 46(7), 1009-1024.

12) SHIMA, H. (1990): Two-dimensional automatic resistivity inversion technique using alpha centers, Geophysics, 55(6), 682-694.

13) SHIMA, H., KAJIMA, K., KAMIYA, H. (1995): New electrical prospecting method for construction, disaster prevention and environment: Resistivity imaging profiling, kokon, 206 $\mathrm{p}^{* *}$

14) SHIMADA, J., KAWAMUKA, R., TANIGUCHI, M. and TSUJIMURA, M. (1992): Continuous soil moisture content measurement at the experimental field of ERC by using the heat-probe type soil moisture sensor, Environmental Research Center Papers, University of Tsukuba, 16, 45$53^{* *}$.

15) TARANTOLA, A. (1987): Inverse problem theory: Method for data fitting and model parameter estimation, Elsevier, $613 p$.

16) TARAntola, A. and VAletTe, B. (1982): Generalized nonlinear inverse problems solved using the least squares criterion, Rev. Geophys. Space Phys., 20, 219-232.

17) ZHANG, J., MACKIE, R. L., and MADDEN, T. R. (1995): 3D resistivity forward modeling and inversion using conjugate gradients, Geophysics, 60 (5), 1313-1325.

\section{Appendix}

$*$ : In Chinese, **: In Japanese

（1997年12月12日受付，1998年11月18日受理）

応用地質，第39巻，第 6 号，524-532頁， 1999

\title{
補修法による三次元土壌比抵抗の逆解析
}

\author{
周啓友・嶋田純・佐藤朗
}

\section{要 旨}

本論文では順問題に有限要素法を用いて，比抵抗卜モグラフィを土袞水時空間変動のモニタリングに応用するための，三次 元土壤比抵抗を逆解析する補修法を提案した。有限要素法の順問題から, 感度の計算, 初期モデルの形成まで, 補修法を利用 して逆解析する各過程を説明した，最後には，補修法の有効性を示すために，2つの数值実験と野外で測定したデー夕の逆解析 についての結果を述べた。この補修法によって，初期土壤比抵抗モデルは計算電位が測定電位に近づくように一歩一歩修正さ れる. 1つの測定イベント（同じ電流電極と入力電流を持っている二極法の測定集まり）はモデル修正の一歩を構成する。この アルゴリズムは1つの測定イベントから得たデータの数がモデルのパラメータ一数より少ない場合, 測定イベントの数が測定機 械の性能或いは探查の目的によって変わる場合, さらに比抵抗が時間とともに变わっている場合にも適応する. 数值実験之野外 で測定したデータの逆解析はこのアルゴリズムの有効性を示した。しかし，土壌表面のみで測定されたデータだけでは，三次 元土壤比抵抗を完璧に再現するには不十分であり，ある程度の土壤内部における測定デー夕あ必要であることが示された。

キーワード : 有限要素法, 逆解析, 土猿比抵抗, 補修法 